\title{
Markov Zinciri Modeli Kullanılarak Kahramanmaraş İli İçin Gelecekteki Hidrolojik Kuraklık Olasılıklarının Belirlenmesi
}

\author{
*Mahmut REIS ${ }^{1}$, Hurem DUTAL ${ }^{1}$ \\ Kahramanmaraş Şütçü İmam Üniversitesi Orman Fakültesi, 46100, Kahramanmaraş/Türkiye \\ *Sorumlu yazar: mreis@ksu.edu.tr
}

Geliş Tarihi: 06.05.2015

\begin{abstract}
Özet
Kuraklık, çok sinsi ilerleyen ve etkileri bakımından diğer afetlerle karşılaştıııldığında daha ciddi zararlara neden olan doğal bir olgudur. $\mathrm{Bu}$ nedenle kuraklığın sürekli olarak takip edilmesi gerekmektedir. Türkiye' nin de taraf olduğu uluslararası sözleşmelerde kuraklığın sürekli olarak izlenilmesi gerektiği vurgulanmaktadır. Bu çalışmada, Markov Zinciri Modeli kullanılarak Kahramanmaraş ili için geleceğe yönelik hidrolojik kuraklık olasılıkları belirlenmiştir. Kuraklık indeksi olarak hem hesaplanmasındaki kolaylık hem de kuraklık olgusunu etkileyen en önemli parametreler olan sıcaklık ve yağışı göz önünde bulundurmasından dolayı "De Martonne" yöntemi seçilmiştir. Kahramanmaraş Meteoroloji İstasyonu' na ait 1970-2013 yıllarını kapsayan 44 yılllı yağış ve sıcaklık verileri kullanılarak her bir yıla ait kuraklık indeks değeri belirlenmiştir. Ardından, kuraklık analizi sonucu elde edilen verilere Markov Zincirleri Yaklaşımı uygulanmıştır. Modelin tahmin kabiliyetinin ortaya konulması amacıyla 2014 yılına ait kuraklık indeksi sınıfı ile 2014 yılı için tahmin edilen her bir kuraklık indeks sınıfının gerçekleşme olasılığ 1 karşılaştırılmıştır. De Martonne kuraklık indeksine göre, Kahramanmaraş' in 2014 yılı için kuraklık indeks değeri 21' dir ve bu değer De Martonne indeksinde "kabul edilebilir sulaklık" sınıfına girmektedir. Modelin 2014 yılı için tahmin ettiği her bir kuraklık sınıfının gerçekleşme olasılıkları ise \%14 "kabul edilebilir kuraklık", \%79 "kabul edilebilir sulaklık" ve \%7 “şiddetli sulaklık” şeklindedir. Model 2015, 2016, 2017, 2018, 2019 ve 2020 yılları için çalıştırıldığında gerçekleşme olasılığı en yüksek olan sınıf, altı yıl için de \%79 gerçekleşme olasılı̆̆ "kabul edilebilir sulaklık" sınıfı olmuştur.

Anahtar kelimeler : Markov Zinciri Modeli, Kuraklık, Kuraklık Prediction, De Martonne Kuraklık İndeksi

\section{Determining Hydrological Drought Probability in Future Using Markov Chain Model for Kahramanmaras City}

Abstract

Drought is an insidious disaster and a naturel phenomenon which causes more serious damage compared to other disasters in terms of its effects. Therefore, it is necessary that drought is monitored consistently. Monitoring drought continuously is emphasized in international conventions which Turkey is engager also. In this study, hydrological drought probabilities in future are determined using markov chain model for Kahramanmaraş city. De Martonne method is chosen as drought index due to both easy calculating and taking into consideration temperature and precipitation which are the most important parameters affecting drought. For each year, drought index value is determined using the precipitation and temperature data involving 1970- 2013 period, total 44 years, of the Kahramanmaraş Meteorology Station. Then, markov chain approach is practiced on data obtained from the result of the drought analysis. With the aim of showing the prediction capacity of the model, drought index class of 2014 year has been compared with the probability of the each drought index class predicted for 2014 year. According to De Martonne drought index, the drought index value of the Kahramanmaraş is 21 for 2014 year and this value is involved in "moderately humid" class. The probability of occurrence of each drought class predicted by model for 2014 year is 14\% "moderately dry", 79\% "moderately humid" and 7\% "extremely humid". When model has been run for 2015, 2016, 2017, 2018, 2019 and 2020 years, class which is the highest probability of occurrence is "moderately humid" with $79 \%$ probability of occurrence for each six year.

Keywords : Markov Chain Model, Drought analysis, Drought prediction, De Martonne Drought Index
\end{abstract}

\section{Giriş}

Kuraklık, yağışın normal düzeyinin oldukça altında olduğu dönemlerde ortaya çıkan ve arazi kaynakları üretim sistemlerini olumsuz biçimde etkileyerek ciddi hidrolojik dengesizliklere yol açan, doğal oluşumlu bir olay olarak tanımlanmaktadır (UNCCD,
1995). Kuraklık, meteorolojik veya klimatolojik, hidrolojik ve tarımsal olarak siniflandirılabilir ve genellikle sosyoekonomik etkilere sahiptir (Keyantash ve Dracup, 2002). Bir bölgedeki meteorolojik veya klimatolojik kuraklık, süresi uzamış ve normalin altındaki nem miktarı ile 
karakterize edilmektedir (Palmer, 1965). Tarımsal kuraklık, meteorolojik kuraklığın değişik karakteristiklerinin tarımsal etkileriyle ortaya çıkmaktadır. $\mathrm{Bu}$ karakteristikler; yağış azlığı, aktüel ve potansiyel evapotranspirasyondaki farklılıklar, toprak suyu yetersizliği, azalmış yeraltı suları veya rezervuar seviyeleri vb. şeklindedir. Hidrolojik kuraklık, yağış eksikliği süresinin yüzey veya yüzey altı su kaynakları (örneğin; dere akımı, rezervuar ve göl seviyeleri, yeraltı suyu) üzerindeki etkisiyle ilişkilendirilmektedir. Hidrolojik kuraklığın frekansı ve șiddeti genellikle havza ölçeğinde tanımlanmaktadır (Monacelli ve ark., 2005). Kuraklığın bir yandan tarıma ve canlılara, diğer yandan da su kaynaklarına ve dolayısıyla da bu kaynaklardan faydalanması gereken endüstrilere etkisi de sosyo-ekonomik kuraklığı oluşturmaktadır (Kurnaz, 2014).

Afetlerin şiddeti, oluşum süreleri, toplam ekonomik kayıp, sosyal etki ve kalıcılığı esas alınarak yapılan değerlendirmede; kuraklık olayı, önem sırasına göre dünyada etkili olan 31 çeşit doğal afet içinde ilk suralarda yer almaktadır (Ilgar, 2010). Toplum hayatında bir çok sektörü etkilemesi ve etki alanının geniş olması nedeniyle kuraklık diğer doğal afetlere göre daha fazla zarar vermektedir. $\mathrm{Bu}$ özelliği ile dünyada dikkatleri üzerine çekmiş ve takip edilmesi için ulusal ve uluslararası birimlerce işbirliği programlarına konu olmuş kuraklığın verdiği zararlar dikkat çekicidir. 1988 yılında Amerika'da meydana gelen kuraklık ekonomik olarak 40 milyar dolar zarara neden olmuştur. Bu zarar 1989 y1lında meydana gelen San Fransisco depreminin verdiği zararın 2-3 katıdır. 2003 yılında Avrupa'da görülen kuraklığın ekonomik zararının en az 8.7 milyar euro olduğu rapor edilmiştir. 1997 yılında Çin' de meydana gelen şiddetli kuraklık 227 gün sürmüştür. Bu sürede Sarı Irmak'ta (Yellow River) hiç akım bulunmamıştır ve bunun kayitlardaki en uzun süre olduğu belirtilmiştir. 2000 yılında Kuzey Çin'de meydana gelen kuraklığın 40 milyon hektarlık bir alanı etkilediği ve bu olayın su kesintileri, çölleşme ve kum firtınalarını tetiklediği rapor edilmiştir. 2006 yılında Avustralya'da meydana gelen kuraklığın tahıl üretimini $\% 36$ oranında azalttığ ve bunun ekonomik değerinin yaklaşık 3,5 milyar Avustralya doları olduğu belirtilmiştir (Mishra ve Singh, 2010).

Dünya Meteoroloji Teşkilatının 87 ülke arasında yapmış olduğu anket sonuçlarına göre, aralarında Türkiye'nin de bulunduğu 74 ülkenin kuraklıktan etkilendiği tespit edilmiştir (WMO, 1992). Kuraklık olayının canlıların yaşamına etki eden can ve mal kayıplarına yol açan diğer doğal afetlerden farkı, etkisinin uzun zamanlı ve daha yavaş hissedilmesidir (Şaylan ve ark., 1997). Yavaş gelişmesi nedeniyle kuraklık, diğer ülkelerde olduğu gibi ülkemizde de farklı kuraklık indeksleri ile sürekli olarak izlenmelidir (Anonim, 1999). Ancak Türkiye'de önemli bir doğal afet olan kuraklığın belirlenmesi, izlenmesi ve ülkenin kuraklıktan etkilenebilirliğini belirlemeyi hedefleyen kuraklık risk çözümlemesi çalışmaları henüz çok yetersiz olmasına karşın son y1llarda küresel 1sınmanın gündeme gelmesiyle birlikte kuraklıkla ilgili çalışmalarda artış göstermiştir (Ilgar, 2010).

Kuraklığın özelliklerini (şiddeti, zamansal ve mekânsal dağılımı) ortaya koymak için birçok kuraklık indisi geliștirilmiștir (Tatlı ve Türkeş, 2011). Bunlardan bazıları SPI(Standardized Precipitation Index) (McKee ve ark., 1993), PDSI(Palmer Drought Severity İndex) (Palmer, 1965), PN(Percent of Normal Precipitation) (Hayes ve ark., 2007) ve Decile (Gibbs ve Maher, 1967) yöntemleridir. Kuraklık analizi için geliştirilen yöntemlerden bir tanesi de "De Martonne kuraklık indeksi" dir. Literatürde, "De Martonne yıllık kuraklık indeksi" birçok araştırıcı tarafindan kullanılmıştır (Güner, 1996)."De Martonne kuraklik indeksi" sadece yağıșı değil aynı zamanda sıcaklığı da göz önünde bulunduran ve hesaplama açısından da kompleks olmayan bir yöntemdir.

Literatürde, kuraklık analizleri çoğunlukla toplam veri setinin amaca yönelik olarak belirlenen $3,6,9,12,24,48 \mathrm{vb}$. ay süreli zaman periyotları için yapılmaktadır. Tarımsal faaliyetler açısından önemli olan kısa ve orta dönem yağış seyrini takip için, 3 aylık kuraklık indeksi sonuçlarının kullanılmasi; yüzey suyu, yeraltı suyu ve rezervuar seviyelerinde meydana gelen kuraklıkları takip etmek için ise daha uzun 
dönem indeks değerlerinin (9-12 aylık) kullanılması daha sağliklı sonuçlar vermektedir (Labedzki, 2007; Hınıs, 2013). Çünkü herhangi bir ayda yağışta meydana gelen azalma toprak nemine hemen etki edebilirken, yer altı sularının ve nehirlerin bundan etkilenmesi daha uzun bir zaman dilimi içinde olmaktadır (Fidan, 2011).

Kuraklık, hemen hemen tüm iklim şartlarında oluşabilen ve yavaş gelişen bir olaydır. Ancak, kuraklığın etkisi bölgeden bölgeye çok fazla değiştiğinden, yapısı oldukça karmaşıktır. Örneğin, tahminin en zor kısmının, kuraklığın başlama zamanı, bitiş zamanı, şiddeti ve frekansı olduğu söylenebilir. Kuraklık bu özelliklerinin değişkenliğinden dolayı, sadece potansiyel bir doğal afet değil, aynı zamanda çok tehlikeli bir olgudur. Kuraklık tehlikelidir; çünkü stokastik bir doğal olaydır ve belirli bir periyoda sahip değildir (Tatlı ve Türkeş, 2011). Literatürde, stokastik olayların modellenmesinde kullanılan farklı yöntemler mevcuttur (Koçak ve Şen 1998). Bu yöntemlerden bir tanesi de "Markov Zincirleri Modeli” dir.

Kahramanmaraş, ülkemizde küresel 1sınmayla birlikte iklim değişikliğinden en fazla etkilenmesi beklenen Akdeniz bölgesinde yer almaktadır. Türkeş (2011), küresel sıcaklıklardaki artışlara bağlı olarak, hidrolojik döngünün değişmesi, kara ve deniz buzullarının erimesi, kar ve buz örtüsünün alansal daralmas1, deniz seviyesinin yükselmesi, iklim kuşaklarının yer değiştirmesi, sıcak hava dalgalarının daha şiddetli ve sı oluşması, bazı bölgelerde aşırı yağışların ve taşkınların, bazı bölgelerde ise kuraklıkların daha şiddetli ve sık oluşması ile yüksek sıcaklıklara bağlı salgın hastalıkların ve zararlıların artması gibi, dünya ölçeğinde sosyoekonomik sektörleri, ekolojik sistemleri ve insan yaşamını doğrudan etkileyecek önemli değişikliklerin beklendiğini belirtmiştir. Küresel 1sınmanın etkisiyle 1901-2012 periyodunda dünya sicaklık ortalamas $10.78{ }^{\circ} \mathrm{C}$ artarken (IPCC, 2014), Kahramanmaraş' ta ortalama sicaklığın 1975-2005 periyodundaki artışı $1.03{ }^{\circ} \mathrm{C}$ ' dir (Cosun ve Karabulut, 2009). Buna göre, Türkiye' nin en büyük su rezervine sahip bölgesinde meydana gelen bu değişim, bölgedeki kuraklık durumunun gelecekte nasıl olacağına yönelik çalıșmaların yapılmasını ve gerekli önlemlerin alınmasını gerektirmektedir. $\mathrm{Bu}$ çalışmada, Kahramanmaraş istasyonuna ait 44 y1llık yağış ve sicaklık verileri kullanılarak kuraklığın tarihsel gelişimi ortaya konulmuş ve markov zincirleri yaklaşımıla gelecekte olması muhtemel kuraklık durumları belirlenmiştir.

\section{Materyal ve Yöntem \\ Materyal \\ Calısma Alanı ve Veri}

Büyük bir bölümü Akdeniz Bölgesi'nin Kuzeydoğu'sunda kalan Kahramanmaraş Havzası Akdeniz İklimi ile Karasal İklim' in geçiş bölgesinde yer almaktadır (Şekil 1). Akdeniz, Doğu Anadolu ve Güneydoğu Anadolu Bölgesi olmak üzere üç coğrafi bölgenin birbirine en fazla yaklaştığ 1 alanda yer alması nedeniyle üç farklı iklim tipi arasında kalmıştır. Kahramanmaraş, bunlardan en fazla Akdeniz İklimi'ne yakın özellik gösterir (Korkmaz, 2001). Kahramanmaraş' ta yıllık ortalama yağış 700 $\mathrm{mm}$ civarındadır. Y1llık ortalama sicaklığ $16.7{ }^{\circ} \mathrm{C}$, maksimum sicaklı̆ 1 $45.2{ }^{\circ} \mathrm{C}$ (Temmuz ayında), minimum sicaklığ 1 ise $9.6{ }^{\circ} \mathrm{C}$ (Şubat ayında)'dır (DMİ, 2010). Kahramanmaras, thornthwaite iklim siniflandırmasina göre (C2 B'3 s2 b'3 ) yar1 nemli, üçüncü dereceden mezotermal, yaz mevsiminde çok kuvvetli su noksanı olan ve denizel şartlara yakın iklim tipine girmektedir. Orman ekosistemin, çılak alanın, çalılıkların, mera ve tarımsal sistemlerin (nadas ve ekili alan) alanda geniş çapta hakim olduğu görülmektedir.

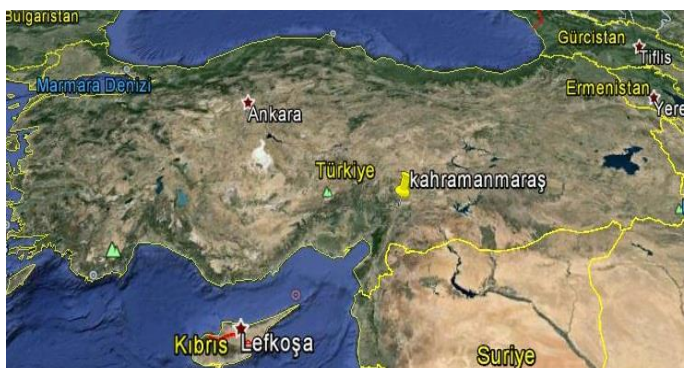

Şekil 1. Çalışma alanının uydu görüntüsü üzerindeki konumu

$\mathrm{Bu}$ çalışmada, Kahramanmaraș merkez istasyonunun uzun süreli yağış ve sıcaklık 
verilerinden yararlanılmıştır. İstasyonun 1970-2013 dönemine ait y1llık ortalama yağış ve yllık ortalama sicaklık verileri kullanılarak kuraklık analizi yapılmış ve elde edilen sonuçlar "Markov Zincirleri Modeli" için girdi olarak kullanılmıştır.

\section{Yöntem}

\section{De Martonne Kuraklık İndeksi}

De Martonne kuraklık indeksi bilimsel literatürde kuraklığın sayısal bir göstergesi olarak kullanılmaktadır. Özellikle, bitki gelişiminde hidrotermal koşullarının değerlendirilmesinde slklıkla kullanılmaktadır. De Martonne kuraklık indeksi, yıllık yă̆ış miktarının(mm) yıllık ortalama sicaklığa $\left({ }^{\circ} \mathrm{C}\right) 10$ eklenerek bulunan değere oranı olarak tanımlanır. De Martonne kuraklık indeksinin yıllık değerini hesaplamak için kullanılan formül:

$$
\operatorname{lm}=\mathrm{P} /(\mathrm{T}+10)
$$

şeklindedir. Eşitlik ( 1 )' de; lm, yıllık kuraklık indeksi; $P$, yıllık yağış miktarı (mm); T, yıllık ortalama sicaklık $\left({ }^{\circ} \mathrm{C}\right) ; 10$, sabit say1 (N1kolova, 2013).

$\mathrm{Bu}$ çalışmada, De Martonne yıllık kuraklık indeksinin siniflandırılması amacıyla Tablo 1' den yararlanılmıştır.

Tablo 1. De Martonne yıllık kuraklık indisi sinıflandırması (Bacanlı ve Saf, 2005)

\begin{tabular}{lc} 
İndeks Değeri & Kuraklık Sınıfı \\
\hline $0-10$ & Aşırı kuraklık \\
\hline $11-15$ & Şiddetli kuraklık \\
\hline $16-20$ & $\begin{array}{c}\text { Kabul edilebilir } \\
\text { kuraklık }\end{array}$ \\
\hline $21-40$ & $\begin{array}{c}\text { Kabul edilebilir } \\
\text { sulaklık }\end{array}$ \\
\hline$\leq 40$ & Şiddetli sulaklık \\
\hline
\end{tabular}

\section{Markov Zincirleri Modeli ve Tahmin}

Günümüzde fiziki, biyolojik, sosyal bilimler ve mühendislik gibi birçok alanda uygulanan Markov süreçleri, Markov tarafından tanımlanmıştır (İnal, 1988). T, dizin (indeks) kümesini göstermek üzere, $X_{t}$ raslantı değişkeninin herhangi bir $\mathrm{t} \varepsilon \mathrm{T}$ zamanında aldığı her değere durum adı verilsin. Tüm olası durumların oluşturdukları kümeye de durum uzayı adı verilsin ve $\mathrm{S}$ ile gösterilsin. Buna göre $\left(X_{t}, t \in T\right)$ biçiminde$$
\mathrm{P}\left(\mathrm{X}_{\mathrm{tn}+1}=\mathrm{X}_{\mathrm{n}}+1 \mid \mathrm{X}_{\mathrm{t} 1}=\mathrm{X}_{1}, \ldots, \mathrm{X}_{\mathrm{t}}\right.
$$

Markov zincirleri, markov süreçlerinin özel bir durumudur ve bir olasılıksal sürecin zaman içinde bulunabileceği farklı durumlar arasında yaptı̆̆ hareketlerin incelenmesinde yaygın olarak kullanılmaktadır (Önalan, 2010). Markov zinciri analizinde, durum, geçiş, geçiş olasılıkları, geçiş olasılıkları matrisi, baslangıç vektörü gibi çeşitli kavramlar büyük öneme sahip olmaktadır. Stokastik süreçte, rassal değişkenlerin aldığı her bir özel değer, bir durum $(s)$ olarak adlandırılırken, sistemin bir durumdan diğerine hareketleri veya durumlar arası değişimleri geçiş olarak ifade edilmektedir gösterilen bir olasıllısal süreç, $\mathrm{S}$ durum uzayında tanımlı ve T zaman indeksli raslantı değişkenler kümesidir. Dizin kümesindeki n sayıda zaman noktasının herhangi bir $\mathrm{t}_{1}<\ldots$ $<t_{n}$ kümesi için, $X_{t 1}, X_{t 2}, \ldots, X_{t n}$ 'in verilen değerlerine göre $X_{\mathrm{tn}+1}$ 'nin koşullu dağılımı yalnızca $X_{t n}$ ' in değerlerine bağlı ise, $\left(X_{t}, t \varepsilon\right.$ T) sürecine Markov süreci adı verilir. Buna göre, herhangi gerçel $\mathrm{x}_{1}, \ldots, \mathrm{x}_{\mathrm{n}}$ sayıları için, Markov eşitliği aşağıdaki gibidir.

$\left.X_{\mathrm{tn}}=\mathrm{X}_{\mathrm{n}}\right)=\mathrm{P}\left(\mathrm{X}_{\mathrm{tn}+1}=\mathrm{X}_{\mathrm{n}+1} \mid \mathrm{X}_{\mathrm{tn}}=\mathrm{X}_{\mathrm{n}}\right)$.

(Winston, 2004). Durum ve geçiş kavramlarından sonra geçiş olasılıkları ve geçiş olasılıkları matrisi kısaca ortaya konmalıdır. Eğer sistem bir periyodda $i$ durumundan gelecek periyodda $j$ durumuna giderse, $i$ 'den $j$ 'ye geçiş olmakta ve bu nedenle Markov zincirinde yer alan pij olasılıkları geçiş olasılıkları (P) olarak adlandırılmaktadır. Geçiş olasılıkları çoğu uygulamada, $s$ durumların sayısını ifade ederken, $s \times$ x $s$ geçiş olasılıkları matrisi $P$ ile gösterilmektedir. Geçiş olasıllkları matrisinin genel notasyonu asağıdaki biçimde olmaktadır. (Winston, 2004): 


$$
\mathrm{P}=\left|\begin{array}{llll}
\mathrm{P}_{11} & \mathrm{P}_{12} & \ldots \ldots \ldots & \mathrm{P}_{1 \mathrm{~s}} \\
\mathrm{P}_{21} & \mathrm{P}_{22} & \ldots \ldots \ldots & \mathrm{P}_{2 \mathrm{~s}} \\
\ldots & \ldots & & \ldots \\
\ldots & \ldots & & \ldots \\
\ldots & \ldots & & \ldots \\
\ldots & \ldots & & \ldots \\
\mathrm{P}_{\mathrm{s} 1} & \mathrm{P}_{\mathrm{s} 2} & \ldots \ldots \ldots & \mathrm{P}_{\mathrm{ss}}
\end{array}\right|
$$

Son olarak, baslanglç vektörü, sistemin veya sürecin mevcut durumunu diğer bir deyişle sistemin $t=0$ periyodunda iken $i$ durumunda olma olasılı̆̆ını, $P(X=i)=q$, ifade etmekte ve $\mathrm{q}=\left|\mathrm{q}_{1} \mathrm{q}_{2} \ldots \mathrm{q}_{\mathrm{s}}\right|$ şeklinde gösterilmektedir (Austin ve Burns, 1985). Markov zincirlerinde yer alan bu araçlardan yararlanılarak $n$-aşamalı geçis olasılıkları hesaplanmaktadir (Stevenson, 1989).

$$
\mathrm{P}\left\{\mathrm{X}_{\mathrm{n}}=\mathrm{j}\right\}=\sum_{i=0}^{s} q P_{i j}^{(n)}
$$

Markov zincirlerinde başlangıç durumları bilinmediğinde, yerine başlangıç durumlarının dağılımını gösteren, başlangıç olasılık vektörü $\mathrm{q}=\left|\mathrm{q}_{1} \mathrm{q}_{2} \ldots \mathrm{q}_{\mathrm{s}}\right|$ kullanılabilir (Taylor ve Karlin, 1984). Bu vektör ve geçiş matrisi kullanılarak zincirin $\mathrm{n}$ adımlı geçiş olasılıkları bulunabilir. Böylece $n$ periyot sonra sistemdeki durumun (yüzdesel) dağılımları, denklem 3 kullanılarak bulunabilir (Akyurt, 2011).

Yukarıda bahsedilen tüm aşamalar hesaplandiktan sonra oluşturulan modelin doğruluğunun test edilmesi modelin kullanımı açısından son derece önemlidir. $\mathrm{Bu}$ nedenle Markov zincirleri modelini test etmek için 2014 yılında gözlenen yıllık yağış ve yıllık ortalama sıcaklık verileri yardımıyla hesaplanan kuraklık indeks değeri kullanılmıştır. 2014 yılı için belirlenen De Martonne kuraklık indeksi sinıfı ile model yardımıyla 2014 yılı için bulunan her bir kuraklık indeksi sınıfının gerçekleșme olasıl1kları karşılaştırılmıştır.

\section{Bulgular ve Tartışma}

\section{De Martonne kuraklık indeksi}

Kahramanmaraş ili için yapılan kuraklık analizinde 1970-2013 yılları arasındaki yıllık toplam yağış ve yıllık ortalama sıcaklık verileri kullanılmıştır. Yapılan analiz sonucunda kuraklık indeks değerlerinin zamana bağlı olarak değişimi çizelge 5' de gösterilmiştir.

Kahramanmaraş' ta 1971, 1972, 1973, 1982, 1990 ve 1999 y1lları "kabul edilebilir kuraklık" sınıfında yer almıştır (Çizelge 1). $\mathrm{Bu}$ durum, yağışlardaki uzun süreli azalma eğilimleri ve belirgin kurak koşulların, özellikle 1970'lerin başından başlayarak, subtropikal kuşağın ve Türkiye'yi de içerecek bir biçimde Akdeniz Havzası'nın önemli bir bölümünde etkili olmasına bağlanabilir (Türkeş, 2012).

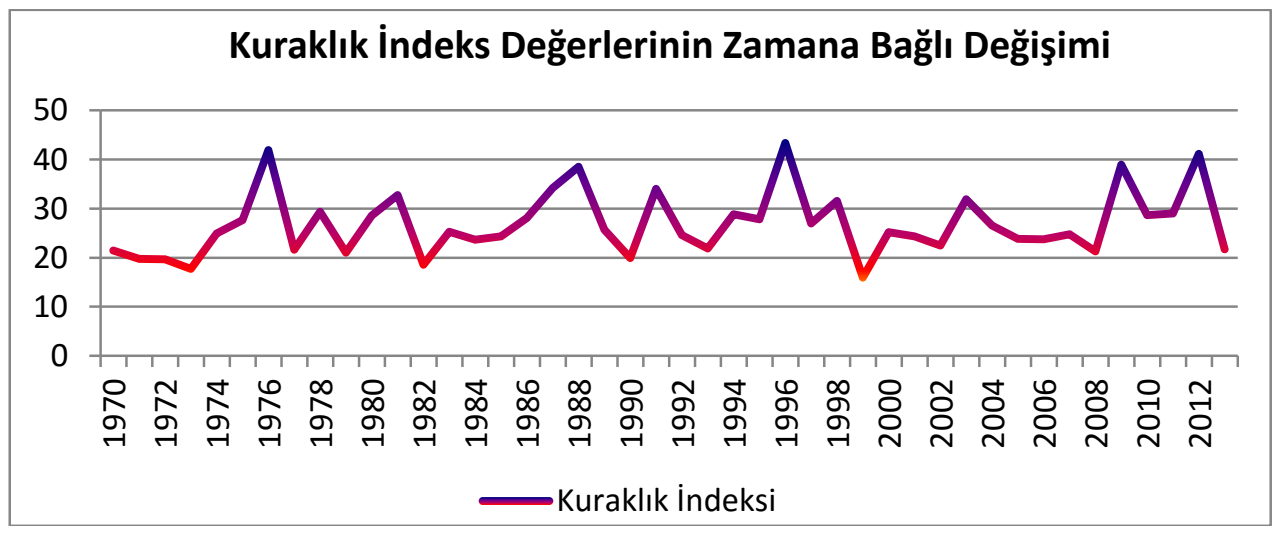

Çizelge 1. Kuraklık indeks değerlerinin zamana bağlı değişimi 
Yukarıda bahsedilen bu kuraklaşma eğiliminden Türkiye'de en fazla, Ege, Akdeniz, Marmara ve Güneydoğu Anadolu bölgeleri etkilenmiştir. Son 40 yılda özellikle kış mevsimi ve yıllık yağış değişiklikleri dikkate alındığında, Türkiye'deki kuraklık olaylarının en şiddetli ve geniş yayılışlı olanları, 1971-1974, 1983-1984, 1989-1990 ve 2007-2008 dönemleri ile 1996 ve 2001 yıllarında oluşmuştur (Türkeş, 1999).

Kahramanmaraş' ta 1999 yılında gözlemlenen kuraklığın şiddeti, çok belirgin bir şekilde görülmektedir (Çizelge 1). Bu yılda meydana gelen toplam yağış miktarı gözlem periyodu içerisindeki en düşük değerdir ve yağış miktarında bir önceki yıla nazaran yaklaşı $\% 50$ oranında azalma olmuştur. $\mathrm{Bu}$ dönemde meydana gelen kuraklık sadece Kahramanmaraş' ta değil Türkiye' nin birçok yerinde gözlemlenmiştir. Türkeş ve ark. (2009), İç Anadolu' nun Konya bölümünde yapmış oldukları çalışmada 1999-2001 döneminde bölgede çok şiddetli bir kuraklığın yaşandığını belirtmişlerdir. Buna paralel olarak Yemen (2013), Van Gölü havzasında yapmış olduğu çalışmasında 1999, 2000 ve 2001 yıllarındaki kuraklık şiddetinin olağanüstü düzeyde seyrettiğini belirtmiştir. Öztürk (2002) Türkiye'de, uzun yıllar yağıș ortalamasının $631 \mathrm{~mm}$ iken, , 1999 yılında yağış miktarının \%15 oranında azaldığını bildirmiştir.

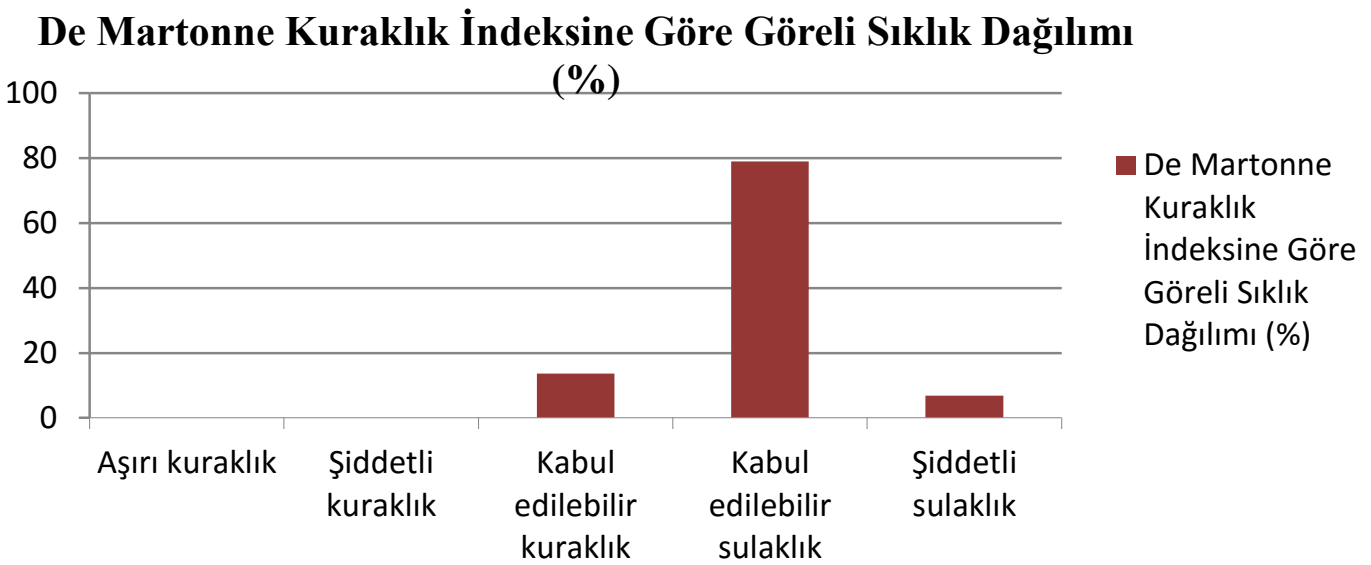

Çizelge 2. De Martonne Kuraklık İndeksine Göre Göreli S1klık Dağılımı

$\begin{array}{llrl}\text { Genel } & \text { olarak } & \text { bakıldığında } \\ \text { Kahramanmaraş'ta } & \text { yarı } & \text { nemli } \\ \text { diyebileceğimiz } & \text { "kabul edilebilir } & \text { sulaklık" } \\ \text { sinıfı hakim olmuştur } & \text { (Çizelge } & \text { 2). }\end{array}$
Kahramanmaraş'ın yıllık ortalama yağış miktarına bakıldığında Türkiye ortalamasının üzerinde olup $700 \mathrm{~mm}$ civarındadır. Bununla birlikte Karabulut ve Cosun (2009), Kahramanmaraş meteoroloji istasyonuna ait verileri kullanarak yapmış olduğu trend analizi çalışmasında Kahramanmaraş'ta uzun dönemler ortalamasına göre toplam yağış miktarında çok önemli bir değişimin olmadığını belirtmiştir.

Yukarıda bahsedilen tüm bu olaylar birlikte değerlendirildiğinde "De Martonne Kuraklık İndeksi" kullanılarak elde edilen sonuçların tatmin edici olduğu görülmektedir.

\section{Markov zincirleri modeli}

Kahramanmaraş istasyonuna ait veriler kullanılarak yapılan kuraklık analizinin sonuçları bölgede ve ülke düzeyinde yapılmış çalışmalarla paralellik göstermiştir. $\mathrm{Bu}$ bölümde, elde edilen bu sonuçlar yardımıyla Markov Zincirleri Modeli oluşturularak geleceğe yönelik kuraklık olasılıkları ortaya konulacaktır.

Modelin ilk aşaması, "De Martonne Kuraklık İndeksi" nin her bir sinıfının markov zinciri modelinde bir $\mathrm{Sj}$ sembolüyle gösterilmesinden oluşmaktadır (Tablo 2).

Geçiş olasılıkları matrisinin bulunması amaciyla, toplam veri periyodundaki her bir yılın kuraklık indeksine karşılık gelen $\left(\mathrm{S}_{\mathrm{j}}\right)$ sembolleri belirlenmiştir (Tablo 3). 
Tablo 2. De martonne kuraklık sınıfları ve markov zincirleri modelindeki karşılıkları

Kuraklık indeks değeri

Sinıfi

Sembol

\begin{tabular}{ccc}
\hline $0-10$ & Aşırı kuraklık & $\mathrm{S}_{1}$ \\
\hline $11-15$ & Şiddetli kuraklık & $\mathrm{S}_{2}$ \\
\hline $16-20$ & Kabul edilebilir kuraklık & $\mathrm{S}_{3}$ \\
\hline $21-40$ & Kabul edilebilir sulaklık & $\mathrm{S}_{4}$ \\
\hline$\leq 40$ & Şiddetli sulaklık & $\mathrm{S}_{5}$
\end{tabular}

Tablo 3.De Martonne indeks değerleri ve markov zincirleri modelindeki karşılıkları

\begin{tabular}{ccccccccc} 
Yıl & $\begin{array}{c}\text { İndeks } \\
\text { değeri }\end{array}$ & $\begin{array}{c}\text { Sembol } \\
\left(\mathbf{S}_{\mathbf{J}}\right)\end{array}$ & $\mathbf{y l l}$ & $\begin{array}{c}\text { Indeks } \\
\text { değeri }\end{array}$ & $\begin{array}{c}\text { Sembol } \\
\left(\mathbf{S}_{\mathbf{J}}\right)\end{array}$ & Yll & $\begin{array}{c}\text { Indeks } \\
\text { değeri }\end{array}$ & $\begin{array}{c}\text { Sembol } \\
\left(\mathbf{S}_{\mathbf{J}}\right)\end{array}$ \\
\hline 1970 & 21 & $\mathrm{~S} 4$ & 1985 & 24 & $\mathrm{~S} 4$ & 2000 & 25 & $\mathrm{~S} 4$ \\
\hline 1971 & 20 & $\mathrm{~S} 3$ & 1986 & 28 & $\mathrm{~S} 4$ & 2001 & 24 & $\mathrm{~S} 4$ \\
\hline 1972 & 20 & $\mathrm{~S} 3$ & 1987 & 34 & $\mathrm{~S} 4$ & 2002 & 22 & $\mathrm{~S} 4$ \\
\hline 1973 & 18 & $\mathrm{~S} 3$ & 1988 & 39 & $\mathrm{~S} 4$ & 2003 & 32 & $\mathrm{~S} 4$ \\
\hline 1974 & 25 & $\mathrm{~S} 4$ & 1989 & 26 & $\mathrm{~S} 4$ & 2004 & 27 & $\mathrm{~S} 4$ \\
\hline 1975 & 28 & $\mathrm{~S} 4$ & 1990 & 20 & $\mathrm{~S} 3$ & 2005 & 24 & $\mathrm{~S} 4$ \\
\hline 1976 & 42 & $\mathrm{~S} 5$ & 1991 & 34 & $\mathrm{~S} 4$ & 2006 & 24 & $\mathrm{~S} 4$ \\
\hline 1977 & 22 & $\mathrm{~S} 4$ & 1992 & 25 & $\mathrm{~S} 4$ & 2007 & 25 & $\mathrm{~S} 4$ \\
\hline 1978 & 29 & $\mathrm{~S} 4$ & 1993 & 22 & $\mathrm{~S} 4$ & 2008 & 21 & $\mathrm{~S} 4$ \\
\hline 1979 & 21 & $\mathrm{~S} 4$ & 1994 & 29 & $\mathrm{~S} 4$ & 2009 & 39 & $\mathrm{~S} 4$ \\
\hline 1980 & 29 & $\mathrm{~S} 4$ & 1995 & 28 & $\mathrm{~S} 4$ & 2010 & 29 & $\mathrm{~S} 4$ \\
\hline 1981 & 33 & $\mathrm{~S} 4$ & 1996 & 43 & $\mathrm{~S} 5$ & 2011 & 29 & $\mathrm{~S} 4$ \\
\hline 1982 & 19 & $\mathrm{~S} 3$ & 1997 & 27 & $\mathrm{~S} 4$ & 2012 & 41 & $\mathrm{~S} 5$ \\
\hline 1983 & 25 & $\mathrm{~S} 4$ & 1998 & 32 & $\mathrm{~S} 4$ & 2013 & 22 & $\mathrm{~S} 4$ \\
\hline 1984 & 24 & $\mathrm{~S} 4$ & 1999 & 16 & $\mathrm{~S} 3$ & & &
\end{tabular}

Tablo 3' de görüldüğü gibi 1970-2013 döneminde en çok gerçekleşen durum S4 sembolüyle gösterilen "kabul edilebilir sulaklik" durumudur. Kahramanmaraş' ta 44 y1llık periyot süresince hiç gerçekleşmeyen durumlar ise S1 (Aşırı kuraklık) ve S2 (Şiddetli kuraklık) durumlarıdır. Tablo 6 kullanılarak oluşturulan geçiş olasılıkları matrisi aşağıda gösterilmiştir. Geçiş olasılıkları matrisi analiz edildiğinde, gözlenen tüm durumların S4 durumuna geçme olasılıkları diğer durumlara geçme olasılıklarından daha fazladır. Diğer bir ifadeyle herhangi bir durumdan sonra gerçekleşme olasılığı en fazla olan durum S4 durumudur.

44 y1llik periyot boyunca S1 ve S2 durumları hiç görülmemiştir. S3 durumundan sonra S3, S4 ve S5 durumlarının görülme olas1likları sirasiyla $0,333,0,667$ ve 0,000 dir. S4 durumundan sonra yine S4 durumunun görülme olasılığı diğer durumlarla karşılaştırıldığında, $\quad 0,794$ olas1likla en yüksektir. S5 durumundan ise sadece S4 durumuna geçiş söz konusudur. Sonuç olarak, sulak durumlara geçme trendinin daha baskın olduğu görülmektedir. 


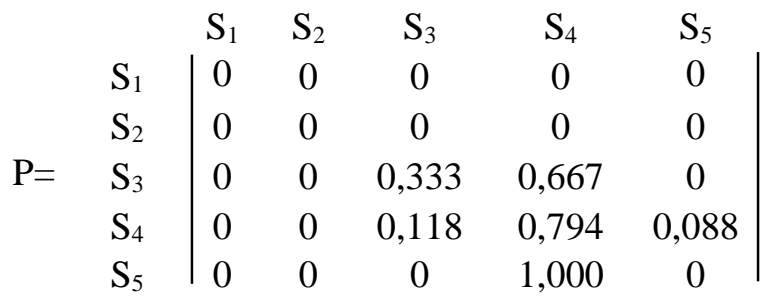

44 yıllık periyot zarfinda her bir $\mathrm{Sj}$ durumunun görülme sıklığı dikkate alınarak oluşturulan $\mathrm{V}^{0} \quad$ (Başlangıç Olasılıkları) vektörü aşağıda verilmiştir.

$$
\mathrm{V}^{0}=\left|\begin{array}{ccccc}
\mathrm{S}_{1} & \mathrm{~S}_{2} & \mathrm{~S}_{3} & \mathrm{~S}_{4} & \mathrm{~S}_{5} \\
0 & 0 & 0,136 & 0,796 & 0,068
\end{array}\right|
$$

Başlangıç ve geçiş olasılıkları yılı için kuraklık olasılıkları belirlenmiştir. hesaplandıktan sonra, modelin Model 2014 yılı için çalıştırıldığında ulaşılan güvenilirliğinin test edilmesi amacıyla 2014 sonuçlar aşağıda $\mathrm{V}^{1}$ vektörü ile gösterilmiştir

$$
\mathrm{V}^{1}=\left|\begin{array}{ccccc}
\mathrm{S}_{1} & \mathrm{~S}_{2} & \mathrm{~S}_{3} & \mathrm{~S}_{4} & \mathrm{~S}_{5} \\
0 & 0 & 0,139126 & 0,790736 & 0,070048
\end{array}\right|
$$

Model çözümü "De Martonne Kuraklık Analizi İndeksi” kriterleri dikkate alındığında ;

Kahramanmaraş' ta 2014 y1lında yaklaşık \%14 olasılıkla "kabul edilebilir kuraklık", \%79 olasılıkla "kabul edilebilir sulaklık", \%7 olasılıkla "şiddetli sulaklık" durumlarının gerçekleşeceğini göstermektedir. Bununla birlikte Kahramanmaraş' ta 2014 yılında "șiddetli kuraklık" ve "așırı kuraklık" durumları beklenmemektedir.

Kahramanmaraş için 2014 yılı verileri kullanılarak belirlenen "De Martonne Kuraklık Analizi İndeksi" nin değeri 21' dir. $\mathrm{Bu}$ değer "De Martonne" sinıflandırmasında "kabul edilebilir sulaklık" $\left(\mathrm{S}_{4}\right)$ sinıfina girmektedir.

Model çözümü değerlendirildiğinde "kabul edilebilir sulaklık" yani $\mathrm{S}_{4}$ durumunun \%79 gerçekleşme olasıllı̆̆ ile en büyük değere sahip olduğu görülmektedir. Sonuc olarak, 2014 y1lında meydana gelen kuraklık durumu, model sonucuna göre gerçekleşme olasılığı en yüksek sınıf içerisinde yer almaktadir.

Model kullanilarak 2015, 2016, 2017, 2018, 2019 ve 2020 yılları için kuraklık tahminleri yapılmıştır. Elde edilen olasılık vektörleri sirasıyla $\mathrm{V}^{2}, \mathrm{~V}^{3}, \mathrm{~V}^{4}, \mathrm{~V}^{5}, \mathrm{~V}^{6}, \mathrm{~V}^{7}$; olarak bulunmuştur

$$
\begin{aligned}
\mathrm{V}^{2} & =\left|\begin{array}{ccccc}
\mathrm{S}_{1} & \mathrm{~S}_{2} & \mathrm{~S}_{3} & \mathrm{~S}_{4} & \mathrm{~S}_{5} \\
0 & 0 & 0,1396658 & 0,7907495 & 0,0695848
\end{array}\right| \\
\mathrm{V}^{3} & =\left|\begin{array}{ccccc}
\mathrm{S}_{1} & \mathrm{~S}_{2} & \mathrm{~S}_{3} & \mathrm{~S}_{4} & \mathrm{~S}_{5} \\
0 & 0 & 0,1398171 & 0,7905969 & 0,0695860
\end{array}\right| \\
\mathrm{V}^{4} & =\left|\begin{array}{ccccc}
\mathrm{S}_{1} & \mathrm{~S}_{2} & \mathrm{~S}_{3} & \mathrm{~S}_{4} & \mathrm{~S}_{5} \\
0 & 0 & 0,1398495 & 0,7905779 & 0,0695725
\end{array}\right| \\
\mathrm{V}^{5} & =\left|\begin{array}{ccccc}
\mathrm{S}_{1} & \mathrm{~S}_{2} & \mathrm{~S}_{3} & \mathrm{~S}_{4} & \mathrm{~S}_{5} \\
0 & 0 & 0,1398581 & 0,7905710 & 0,0695709
\end{array}\right| \\
\mathrm{V}^{6} & =\left|\begin{array}{ccccc}
\mathrm{S}_{1} & \mathrm{~S}_{2} & \mathrm{~S}_{3} & \mathrm{~S}_{4} & \mathrm{~S}_{5} \\
0 & 0 & 0,1398601 & 0,7905696 & 0,0695703
\end{array}\right| \\
\mathrm{V}^{7} & =\left|\begin{array}{ccccc}
\mathrm{S}_{1} & \mathrm{~S}_{2} & \mathrm{~S}_{3} & \mathrm{~S}_{4} & \mathrm{~S}_{5} \\
0 & 0 & 0,1398606 & 0,7905692 & 0,0695701
\end{array}\right|
\end{aligned}
$$


Sonuçlara bakıldığında kuraklık olasılıklarının birbirine çok yakın değerler aldığ1 görülmektedir. Bu nedenle 2015,

$$
\mathrm{V}^{2,3,4,5,6,7}=\left|\begin{array}{ccccc}
\mathrm{S}_{1} & \mathrm{~S}_{2} & \mathrm{~S}_{3} & \mathrm{~S}_{4} & \mathrm{~S}_{5} \\
0 & 0 & 0,14 & 0,79 & 0,07
\end{array}\right|
$$

$\mathrm{Bu}$ sonuçlara göre; Kahramanmaraș' ta 2015, 2016, 2017, 2018, 2019 ve 2020 yıllarında gerçekleșmesi muhtemel kuraklık olas1lıklar1 \%79 "kabul edilebilir sulaklık", \%14 "kabul edilebilir kuraklık" ve \%7 "aşırı sulaklık" durumları iken "așırı kuraklık" ve "şiddetli kuraklık" durumlarının gerçekleşme olasilıkları \%0” dir.

Kahramanmaraş ' ta 2015, 2016, 2017, 2018, 2019 ve 2020 yillarında gerçekleşme olasılığ1 \% 79 olasılıkla en fazla olan S4 durumunun, bu 6 yıl içinde üst üste gerçekleşme olasıllı̆̆ ise \% $25^{\prime}$ dir.

\section{Sonuc}

Kahramanmaraș için hidrolojik kuraklık olasılıklarının tahmin edildiği bu çalıșmanın sonuçları; (i) Kahramanmaraş ta 2015, 2016, 2017, 2018, 2019 ve 2020 periyodunda yaklașık \%79 olasılıkla "kabul edilebilir sulaklık" sınıfi hakim olacaktır, (ii) bu sonuç dikkate alındığında ilgili periyot süresince Kahramanmaraş' ta su rezervleri, yer altı ve yer üstü su kaynaklarında büyük bir kuraklık olayı beklenmemektedir, (iii) S4 durumunun 2015-2020 y1lları boyunca üst üste görülme olasılı̆̆1 \% 25' dir ve (iv) Kahramanmaraş “ taki mevcut hidrolojik kuraklık olasılıklarının en az 2020 yılına kadar değişime uğramayacağı șeklindedir.

\section{Kaynaklar}

Akyurt İ. Z. 2011. Ülke Derecelendirme Sisteminin Markov Zinciri İle Analizi. Yönetim Dergisi, y1l: 22, sayı: 69.

Anonim 1999. Meteorolojik Karakterli Doğal Afetler ve Meteorolojik Önlemler, TMMOB Meteoroloji Müh. Odası, Ankara.

Austin L. M., Burns J. R. 1985. Management Science: An Aid for Managerial Decision Making. Macmillan Publishing Company: New York.

Bacanlı Ü. G., Saf B. 2005. Kuraklık Belirleme Yöntemlerinin Antalya İli Örneğinde
2016, 2017, 2018, 2019 ve 2020 y1llar1 için elde edilen tahmin değerleri genel olarak $V^{2,3,4,5,6,7}$ şeklinde gösterilmiştir.

İncelenmesi. Antalya Yöresinin İnşaat Mühendisliği Sorunları Sempozyumu, 2225/09/2005, Antalya, Türkiye.

Cosun F., Karabulut M. 2009. Kahramanmaraş' ta Ortalama, Minimum ve Maksimum Sicaklıkların Trend Analizi. Türk Coğrafya Dergisi Sayı 53: 41-50.

DMİ 2010. Devlet Meteoroloji İşleri Gn. Md., K.Maraş Meteoroloji İl Müdürlüğü, K.Maraș Meteoroloji İstasyonu Verileri, 1975-2010, Kahramanmaraş.

Fidan İ. H., 2011. Doğu Akdeniz Bölgesinde Standardize Yağış İndeksi (SYİ) İle Kuraklık Analizi Ve Markov Zinciri Yöntemini Kullanarak Kurak Olma Olasılıklarının Belirlenmesi. Yüksek Lisans Tezi, Çukurova Üniversitesi Fen Bilimleri Enstitüsü, Adana.

Gibbs W.J., Maher J.V. 1967. Rainfall Deciles as Drought İndicators. Australian Bureau of Meteorology; 48: 37 pp.

Güner Ü., 1996. Büyük Menderes Havzas1 Kuraklık Çözümlemesi. Yüksek Lisans Tezi, Pamukkale Üniversitesi Fen Bilimleri Enstitüsü, Denizli.

Hayes M. J., Alvord C., Lowrey J. 2007. Drought Indices. Feature Article From Intermountain West Climate Summary, July.

Hınıs M.A. 2013. Bütünleşik Kuraklık İndeksi İle Aksarayda Hidrometeorolojik Kuraklık Analizi. Journal of the Faculty of Engineering and Architecture of Gazi University, Vol 28, No 4, 711-721. Ilgar R. 2010. Çanakkale'de Kuraklık Durumu Ve Eğilimlerinin Standartlaştırılmış Yağış İndisi İle Belirlenmesi. Marmara Coğrafya Dergisi Sayı: 22, Temmuz - 2010, S. 183 - 204 Issn:1303-2429.

IPCC 2014. Climate Change 2014: Synthesis Report. Contribution of Working Groups I, II and III to the Fifth Assessment Report of the Intergovernmental Panel on Climate Change [Core Writing Team, R.K. Pachauri and L.A. Meyer (eds.)]. IPCC, Geneva, Switzerland, 151 pp.

İnal C. 1988. Olasılıksal Süreçlere Giriş, Hacettepe Üniversitesi Yayınları, Ankara. 
Karabulut M., Cosun F. 2009. Kahramanmaras İlinde Yağısların Trend Analizi. Coğrafi Bilimler Dergisi CBD 7 (1), 65-83.

Keyantash J., Dracup J. A. 2002. The Quantification of Drought : An Evaluation of Drought Indices. Bulletin Of American Meteorological Society: 1167-1180.

Koçak K., Şen Z. 1998. Kurak ve Yağışlı Gün Oluşumlarının Markov Zinciri Yaklaşımı ile Uygulamalı İncelenmesi. Tr. J. of Engineering and Environmental Science, 22, 479 - 487.

Korkmaz H., 2001. K.Maraş Havzası'nın Jeomorfolojisi. Doktora Tezi, Marmara Üniversitesi Sosyal Bilimler Enstitüsü, İstanbul.

Kurnaz L. 2014. Kuraklık ve Türkiye. Mart 2014 IPM-Mercator Politika Notu.

Labedzki L. 2007. "Estimation of Local Drought Frequency in Central Poland Using The Standardized Precipitation Index SPI", Irrigation and Drainage, 56, 67-77.

McKee T. B., Doesken N.J., Kleist J. 1993. The relationship of drought frequency and duration to time scales. Preprints, AMS 8th Conference on Applied Climatology, pp. 179184. January 17-22, Anaheim, CA.

Mishra A., Singh A.P. 2010. "A review of drought concepts", Journal of Hydrology, 391, 202-216.

Monacelli G., Galluccio M. C., Abbafati M. 2005. Drought Within The Context Of The Region V. Italian Agency for Environmental Protection and Technical Services (APAT), Hydrology and Inland Waters Service.

Nikolova N. 2013. The impact of the drought on the main crops cultivated in Northeastern Bulgaria. Forum geografic. Studii și cercetări de geografie și protecția mediului Volume XII, Issue 1 (June), pp. 16-24 (9).

Önalan Ö. 2010.Stokastik Süreçler, Avcıol Basım Yayın, İstanbul.

Öztürk K. 2002. Küresel İklim Değişsikliği ve Türkiye'ye Olası Etkileri. G.Ü. Gazi Eğitim Fakültesi Dergisi Cilt 22, Sayı 1, 47-65.

Palmer W.C. 1965. Meteorological drought. Research Paper No: 45, U.S. Departman of Commerce, Weather Bureau, Washington, D.C.

Stevenson W. J. 1989. Introduction to Management Science. Irwin Inc.:USA.
Şaylan L., Durak M., Şen O. 1997. Kuraklık ve Etkileri, Meterolojik Karakterli Doğal Afetler Sempozyumu, Bildiriler Kitab1, s.433-444, Ankara, Türkiye.

Tatlı H., Türkeş M. 2011. Palmer Kuraklık Şiddeti ve Standartlaştırılmış Yağış İndislerinin Türkiye Üzerinde Karşılaștırılması. $5^{\text {th }}$ Atmospheric Science Symposium, İstanbul Technical University, İstanbul, Turkey.

Taylor H. M., Karlin S. 1984. An Introduction To Stochastic Modeling, Orlando, Florida, Academic Press, Inc.

Türkeş M. 1999. Vulnerability of Turkey to desertification with respect to precipitation and aridity conditions. Turkish Journal of Engineering and Environmental Sciences 23, 363-380.

Türkeş M. 2011. Akhisar ve Manisa Yörelerinin Yağış ve Kuraklık İndisi Dizilerindeki Değişimlerin Hidroklimatolojik ve Zaman Dizisi Çözümlemesi ve Sonuçların Çölleşme Açısından Coğrafi Bireşimi. Coğrafi Bilimler Dergisi CBD 9 (1), 79-99.

Türkeş M. 2012. Kuraklık, Çölleşme ve Birleşmiş Milletler Çölleşme İle Savaşım Sözleşmesi'nin Ayrıntılı Bir Çözümlemesi. Marmara Avrupa Araştırmaları Dergisi, cilt: 20, say1: 1.

Türkeş M., Akgündüz A. S., Demirörs Z. 2009. Palmer Kuraklık İndisi'ne Göre İç Anadolu Bölgesi'nin Konya Bölümü'ndeki Kurak Dönemler Ve Kuraklık Şiddeti. Coğrafi Bilimler Dergisi CBD 7 (2), 129-144.

UNCCD 1995. 'The United Nations Convention to Combat Desertification in those Countries Experiencing Serious Drought and/or Desertification, Particularly in Africa, Text with Annexes'. Geneva:United Nations Environment Programme (UNEP).

Winston W. L. 2004. Operations ResearchApplications and Algorithms. Brooks/Cole, Fourth Ed: USA.

WMO 1992. Monitoring, Assesment and Combat of Drought and Desertification, Ceneva, TD-No.55.

Yemen H. 2013. Van Gölü Havzası'nın Kuraklı Analizi. 21. Yüzyılda Eğitim ve Toplum, Cilt 3 Say1 5. 